\title{
STUDY OF OUTCOME FOLLOWING NAIL DYNAMIZATION FOR TREATING DELAYED HEALING FEMORAL SHAFT FRACTURES
}

\author{
Vidya Bhushan Singh ${ }^{1}$, Amit Chaurasia' 2 P. K. Lakhtakia ${ }^{3}$ \\ ${ }^{1}$ Assistant Professor, Department of Orthopaedics, S. S. Medical College, Rewa, Madhya Pradesh. \\ ${ }^{2}$ Associate Professor, Department of Orthopaedics, S. S. Medical College, Rewa, Madhya Pradesh. \\ ${ }^{3}$ Professor, Department of Orthopaedics, S. S. Medical College, Rewa, Madhya Pradesh.
}

\begin{abstract}
BACKGROUND: Dynamisation of a previously interlocked intramedullary nail is believed to stimulate an osteogenic response and accelerate union due to increased load across the fracture site.

OBJECTIVE: This retrospective study evaluated the role of dynamization of interlocking nails to treat the delayed heeling femoral fractures.

MATERIAL AND METHODS: Eighteen static femoral interlocking nails were dynamized after 4 months (Range 3-6 months) because of poor fracture healing. The clinical and radiographic healing processes were recorded. All the cases were followed up to monitor the progress of fracture healing till their end results in the form of union or non-union.

RESULTS: The time between interlocking nailing and nail dynamization was ranging between 3 to 6 (Mean 4 months). After the dynamization cases were followed for at least 6 months (Range, 4-8 months) twelve patients (66.6\%) achieved a solid union, within a union period of 5.4 months (Range, 3-8 months) after dynamization. One patient achieved union with more than $2 \mathrm{~cm}$ of femoral shortening.
\end{abstract}

CONCLUSION: Not all cases achieve union after dynamization. It should be reserved for delayed healing axially stable fractures.

KEYWORDS: Femoral Shaft Fracture, Delayed Union, Dynamization.

HOW TO CITE THIS ARTICLE: Vidya Bhushan Singh, Amit Chaurasia, P. K. Lakhtakia. "Study of Outcome Following Nail Dynamization for Treating Delayed Healing Femoral Shaft Fractures." Journal of Evolution of Medical and Dental Sciences 2015; Vol. 4, Issue 93, November 19; Page: 15893-15895, DOI: 10.14260/jemds/2015/2309.

INTRODUCTION: Intramedullary nailing was introduced in the treatment of femoral shaft fractures resulting in excellent union. ${ }^{1}$ Interlocking nailing provides more rotational stability for fixation of the fracture. Closed intramedullary nailing is a recent treatment for femoral shaft fractures. ${ }^{2,3}$ Repair of fractures involves a sequence of dynamic events, which ultimately restores the integrity of the bone and its

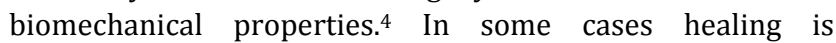
compromised leading to delayed union or nonunion. It is estimated that $10 \%$ of the fractures, which occur annually will require further surgical procedures because of impaired healing. ${ }^{5}$ Einhorn reported definitions for nonunion and delayed union that move beyond a simple time line describing nonunion as the cessation of all healing processes and union has not occurred.

He further defines delayed union as a continuation of healing processes, but union has not occurred in the expected time, and the outcome is uncertain. ${ }^{6}$ Dynamization of a previously interlocked intramedullary nail is a simple method for treating femoral shaft fractures (FSF) in patients with delayed healing after intramedullary nailing and is believed to stimulate an osteogenic response due to increased load across the fracture site. In this study, we retrospectively investigated the effects of dynamization of static interlocking nails to promote union in FSF patients with delayed healing and the adverse effects of dynamization.

Financial or Other, Competing Interest: None.

Submission 08-11-2015, Peer Review 09-11-2015,

Acceptance 11-11-2015, Published 19-11-2015.

Corresponding Author:

Dr. Vidya Bhushan Singh,

F-10, Doctor's Colony,

S. S. Medical College Campus,

Rewa, Madhya Pradesh, India

E-mail: dr.vidyabhushan.singh@gmail.com

DOI:10.14260/jemds/2015/2309.
METHOD: Eighteen consecutive acute FSF patients with static locking intramedullary nails who developed delayed union and subsequently underwent dynamization were recruited between August 2011 and April 2015. The indication for the dynamization was the persistence of gap or absence of bridging callus at the fracture site after 3 months of statically locked intramedullary femoral nailing. Exclusion criteria were established non-union, dynamization after 6 months of nailing, infection at the fracture site and severely unstable fracture patters that had tendency to develop unacceptable shortening and deformity.

Fourteen patients were male and 4 were female with a mean age of 34 years. Sixteen cases were due to road side accidents and 2 were due to falls from a height. Eleven cases had open fractures and 7 had closed ones. The fractures were located at the middle $1 / 3$ in 10 cases and at the distal $1 / 3$ in 8. According to the Winquist-Hansen classification, there were 5, 3, 7 and 3 types I, II, III and IV fractures, respectively. Reamed nails were used for 16 fractures and unreamed nails were used for 2. All the cases of delayed union had been nailed in static mode initially and underwent later dynamization by removing interlocking bolts away from the fracture site. All the cases were followed up to monitor the progress of fracture healing till their end results in the form of union or non-union.

RESULT: The time between interlocking nailing and nail dynamization was ranging between 3 to 6 (Mean 4 months). Complete union (Within 6 months after dynamization) was achieved in 9 patients without significant femoral shortening. One patient with unstable fracture pattern united with significant femur shortening $(>20 \mathrm{~mm})$. Two cases took longer than 6 months $\left(7^{\text {th }}\right.$ and $8^{\text {th }}$ post-dynamization months) to achieve complete union. 
In the remaining 6 cases non-union developed. Thus 12 of the 18 cases (66.6\%) achieved union after the dynamization.

DISCUSSION: Several textbooks have proposed definitions for delayed healing based upon time 3-4 months for delayed union and 6-8 months for non-union. ${ }^{7}$ Non-union of the femoral shaft is usually defined as a failure to achieve clinical union at 6-12 months following fixation or if there is no healing progress during the last 3 months or an implant failure is obvious. ${ }^{8-11}$ Dynamization of a static interlocking nail offers a theoretically sound and minimally invasive treatment option for the management of delayed and nonunion. Although, it has also been credited with accelerating the rate of union in delayed unions.12-14 dynamization, or dynamic interlocking nailing, has also been blamed for causing loss of reduction and shortening in comminuted femoral shaft fractures. ${ }^{15-16}$

Furthermore, benefits of dynamization and the timing of it is still very controversial.17-19 In our study 12 of 18 $(66.6 \%)$ patients with delayed union achieved complete union after the nail dynamization. In a similar study $\mathrm{Wu} .{ }^{11}$ reported a 58\% union rate after dynamization, performed 6 months on average after the initial procedure. More than 2 $\mathrm{cm}$ of femoral shortening was noted in $21 \%$ of these patients. Basumallick and Bandopadhyay. ${ }^{20}$ in a prospective randomized comparative study found that although dynamization after open interlocking nailing significantly shortens the mean time to union, there are no significant differences between the union rates in the dynamized and non-dynamized groups.

In the present study, the fractures were dynamized between 3 and 6 months postoperatively, since it was felt that dynamization 6 to 8 months after operation may be too late and by that time all biological efforts to achieve union would have exhausted. In the present study, six patients with delayed union did not respond with dynamization. The possible factors affected the union would be compound and comminuted nature of most of them. According to Boyd et al.21 the following local factors should be taken under consideration for non-union of long bones: Open fractures, infection, segmental fractures with impaired blood supply to the middle fragment, comminuted fractures due to severe trauma, insecurely fixed osteosynthesis, ill-advised open reduction, and distraction by traction.

In our study it was observed that dynamization alone provided only a $66 \%$ chance of bone union and duration of achieving union varied from within 6 months, in most of cases to more than 6 months in some. It was also observed that most of patients that achieved union had some distraction at the fracture site and were dynamized early without waiting much, whereas most of those who landed up with non-union had high velocity bone and soft tissue injuries.

CONCLUSION: In my experience, however, not all cases achieve union after dynamization. It should be reserved for delayed healing axially stable fractures without significant angular deformity, particularly if they are statically locked in distraction.

\section{REFERENCES:}

1. Hansen ST, Solvik S: Treatment of unstable femoral shaft fractures with closed interlocking intramedullary nailing. J Orthop Trauma, 1: 209-218, 1987.

2. Banaszkiewicz PA, Sabboubeh A, McLeod I, Maffulli N: Femoral exchange nailing for aseptic non-union: Not the end to all problems. Injury, 34: 349-356, 2003.

3. Wolinsky PR, McCarty E, Shyr Y, Johnson K: Reamed intramedullary nailing of the femur: 551 cases. J Trauma, 46:392-399, 1999.

4. Einhorn TA. The cell and molecular biology of fracture healing. Clin Orthop 1998; 355(Suppl l), 7-21.

5. Einhorn TA. Enhancement of fracture healing. J Bone Joint Surg Am 1995; 77: 940-56.

6. Einhorn TA. Breakout session 1: Definitions of fracture repair. Clin Orthop 1998; 355 (Suppl 1), S353.

7. Rüedi T, Murphy W. AO Principles of Fracture Management. Thieme, Stuttgart, 2000.

8. Cove JA, Lhowe DW, Jupiter JB, et al. The management of femoral diaphyseal non-unions. J Orthop Trauma 1997; 11: 513-20.

9. Furlong AJ, Giannoudis PV, DeBoer P, et al. Exchange nailing for femoral shafts aseptic non-union. Injury 1999; 30: 245-9.

10. Banaszkiewicz P, Sabboubeh A, McLeod I, et al. Femoral exchange nailing for aseptic non-union: not the end to all problems. Injury 2003; 1812:1-8.

11. Wu CC, Shih C, Chen W, et al. Effect of reaming bone grafting on treating femoral shaft aseptic nonunion after plating. Arch Orthop Trauma Surg 1999; 119: 303-7.

12. Brumback R. J., Reilly J. P., Poka A., Lakatos R. P., Bathon G. H., Burgess A. R. Intramedullary nailing of femoral shaft fractures. Part I: Decision-making errors with interlocking fixation. J. Bone Joint Surg., 1988, 70-A, 1441-1452.

13. Wiss D. A., Brien W. W., Stetson W. B. Interlocked nailing for treatment of segmental fractures of the femur. J. Bone Joint Surg., 1990, 72-A, 724-728.

14. Wiss D. A., Fleming C. R, Matta J. M., Clark D. Comminuted and rotationally unstable fractures of the femur treated with an interlocking nail. Clin. Orthop. 1986, 212, 35-47.

15. Brumback R. J., Uwagi-Ero S., Lakatos R. P., Poka A., Bathon G. H., Burgess A. R. Intramedullary nailing of femoral shaft fractures. Part II: Fracture-healing with static interlocking femoral fixation. J. Bone Joint Surg., 1988, 70-A, 1453-1462.

16. Christie J., Court-Brown C., Kinniworth A. W., Howie C. Intramedullary locking nails in the management of femoral shaft fractures. J. Bone Joint Surg., 1988, 70-B, 206-210.

17. Wu C. C. The effect of dynamization on slowing the healing of femur shaft fractures after interlocking nailing. J. Trauma, 1997, 43, 263-267.

18. Wu C. C., Chen W. J. Healing of 56 segmental femoral shaft fractures after locked nailing. Poor results of dynamization. Acta Orthop. Scand., 1997, 68, 537-540.

19. Wu C. C., Shih C. H. Effect of dynamization of a static interlocking nail on fracture healing. Can. J. Surg., 1993, $36,302-306$. 
20. Basumallick M, Bandopadhyay A. Effect of dynamization in open interlocking nailing of femoral fractures. A prospective randomized comparative study of 50 cases with a 2-year follow-up. Acta Orthop Belg 2002; 68: $42-8$.
21. Boyd HB, Lipinski SW, Wiley JH. Observations on nonunion of the shafts of the long bones with a statistical analysis of 842 patients. J Bone Joint Surg Am 1961; 43-A: 159-68.

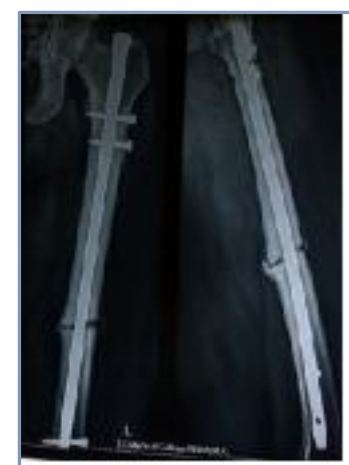

X-ray showing delayed union

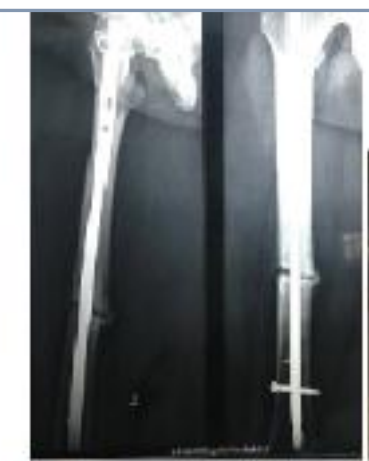

$X$-ray 4 months after nail dynamization showing nonunion

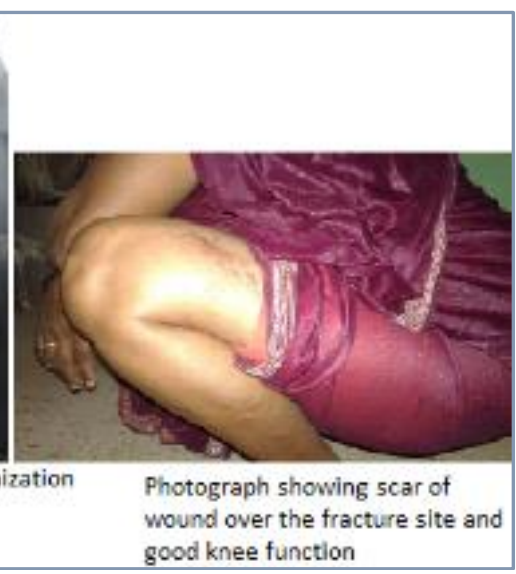

good knee function

Fig. 1

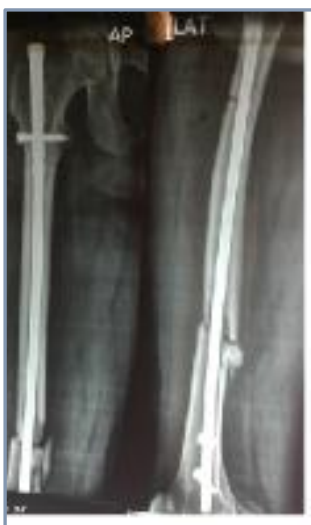

X-ray showing delayed union 4 months after

closed interlocking nailing

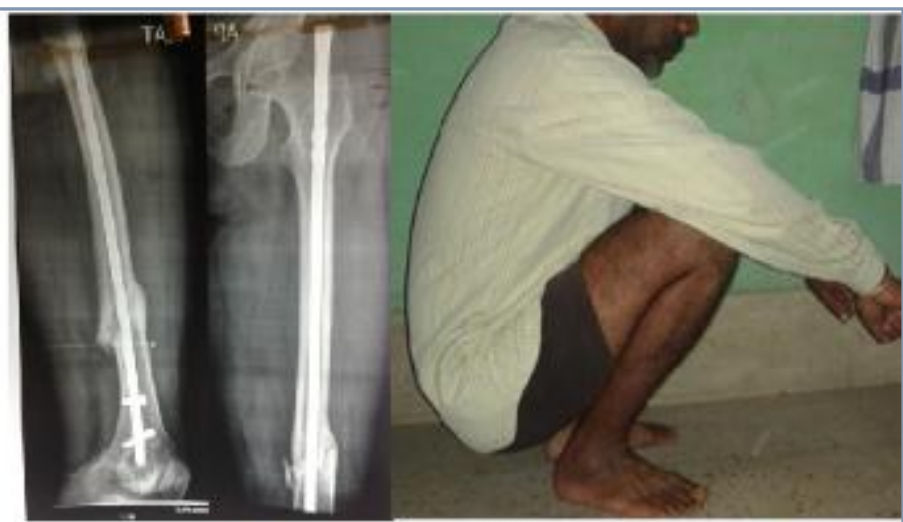

$X$-ray and clinical photograph showing complete fracture union and excellent function function 3 months after the dymamization

Fig. 2

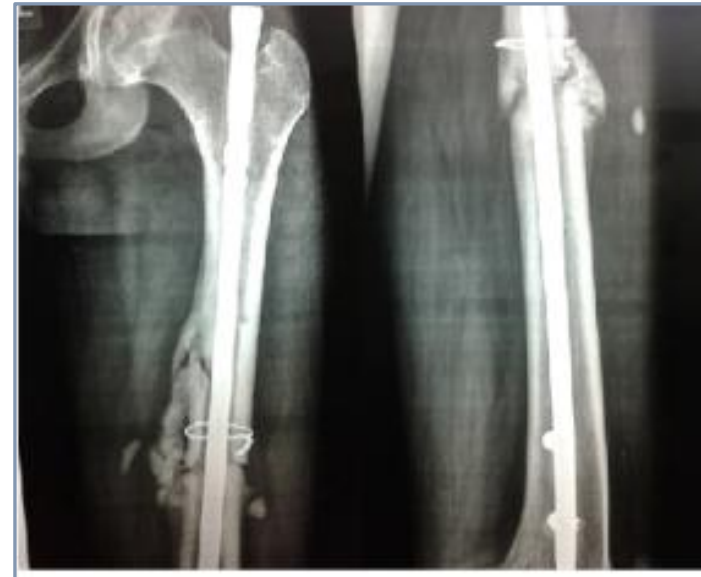

$X$-ray showing nonunion of comminuted fracture shaft femur in which interlock nailing and bone grafting was done 8 months ago and dynamized 5 months later to treat delayed union.

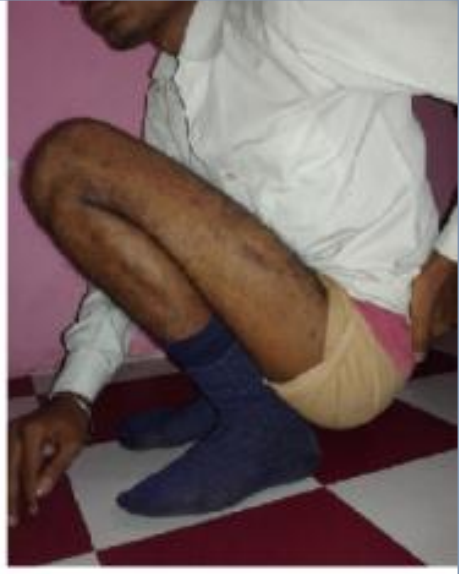

Photograph showing scar of wound over the fracture site and good knee function even after nonunion.

Fig. 3 